\title{
Vector Sum Analysis Method of Loess Slope Stability under Rising Groundwater Level Conditions
}

\author{
Haibin Xue $\mathbb{D}^{1},{ }^{1}$ Faning Dang, ${ }^{1}$ Yanlong Li, ${ }^{1}$ Xiaotao Yin, $^{2}$ and Man Lei ${ }^{1}$ \\ ${ }^{1}$ State Key Laboratory of Eco-Hydraulics in Northwest Arid Region, Xi'an University of Technology, Xi'an 710048, China \\ ${ }^{2}$ State Key Laboratory of Geomechanics and Geotechnical Engineering, Institute of Rock and Soil Mechanics, \\ Chinese Academy of Sciences, Wuhan 430071, China \\ Correspondence should be addressed to Haibin Xue; xhbyts2013@163.com
}

Received 4 April 2019; Revised 22 June 2019; Accepted 9 September 2019; Published 16 October 2019

Academic Editor: Zaobao Liu

Copyright (C) 2019 Haibin Xue et al. This is an open access article distributed under the Creative Commons Attribution License, which permits unrestricted use, distribution, and reproduction in any medium, provided the original work is properly cited.

\begin{abstract}
The stability analysis of loess slopes with a rising groundwater level is a problem that integrates unsaturated and transient seepage, stress analysis, and stability prediction. For this purpose, a sequentially coupled method of seepage-softening-stability was used. First, seepage analysis of a loess slope with a rising groundwater level was conducted according to unsaturated and transient seepage analysis theory. Second, the spatial distribution of the deformation and strength parameters of the soil, both of which were based on the calculated results of the seepage analysis, were adjusted according to the water-induced structural deterioration equation. Third, the vector sum analysis method of loess slope stability, which was based on the temporal-spatial distribution laws of effective unit weight, elastic modulus, Poisson's ratio, cohesion, internal friction angle, and seepage force, was performed by the body force method. To verify the proposed method, the limit equilibrium method of loess slope stability was conducted by the surface force method. Finally, the progressive failure process of a loess slope with a rising groundwater level on the White Deer Plain was presented as an example. A comparison analysis of the calculated results of the two methods revealed that the proposed method was reasonable and reliable.
\end{abstract}

\section{Introduction}

The Loess Plateau has the most widely distributed and most completely developed loess, and it is the only young plateau in the world. In recent years, the implementation of major national strategies, such as "the Western Development" and "the Belt and Road," has provided unprecedented development opportunities for the Loess Plateau. With the construction of large-scale projects, such as highways, highspeed railways, and hydraulic engineering, the problems of loess slope engineering will become increasingly prominent. Therefore, studying the stability analysis of loess slopes will ensure the safety of people's lives and property and promote the implementation of China's major strategies. However, the formation mechanism and failure mode of loess disasters are determined by special mechanical properties, including loess structure, water sensitivity, collapsibility, and anisotropy $[1,2]$. Thus, the stability analysis of loess slopes differs from conventional slope stability analysis.
Scholars have achieved progress in the quantitative analysis of loess slope stability, which can generally be approached in two ways. One is establishing the quantitative parameters of the loess structure, followed by analyzing the relationship between the quantitative parameters and strength parameters and studying the loess slope stability at last, which is considered the thought of comprehensive structural potential [1]. According to the Mohr-Coulomb yield criterion, stress structural parameters and stress ratio structural parameters were introduced to reflect the strength characteristics of structural soil $[3,4]$. Slope stability has been analyzed by the strength reduction method, thereby forming a stability analysis method for structural loess slopes. The structural parameters were then redefined on the basis of the results of Chen's work [5]. The structural parameters were divided into initial and perturbed structural parameters for a reasonable definition of the structural parameters. In this way, the loess slope stability analysis method considers the initial structural parameter. Zheng 
introduced the structural parameters into the joint strength criterion of the loess and proposed a loess slope stability analysis method that considers the tensile strength [6]. These achievements were realized through the strength reduction method. Nonetheless, the contradiction between the way of strength reduction and the deterioration law of structure must be further explored.

The other is finding the main controlling factor that reduces the slope strength parameters and then establishing the relationship among the deformation parameters, the strength parameters, and the main controlling factor, i.e., the deterioration equation, which is then integrated into the traditional slope stability analysis method to analyze the changes of the slope safety factor. This approach is the seepage-softening-stability analysis method, which is generally applied in the stability analysis of soft rock slopes rather than loess slopes $[7,8]$. In this framework, the failure mechanism of a loess slope can be revealed if the vector sum analysis method can be introduced into the stability analysis of the loess slope because the safety factor of the vector sum analysis method has a more concrete meaning $[9,10]$.

The stability analysis of loess slopes with a rising groundwater level integrates unsaturated and transient seepage, stress analysis, and stability prediction. To deal with it reasonably, first, we must solve the problem of unsaturated seepage analysis under rising groundwater level conditions. Second, we must address the problem of stress-strain analysis with respect to the structural characteristic of the loess. Third, we must solve the problem of slope stability analysis on the basis of the spatial distribution laws of the stress and strength parameters. Only by solving these three problems can we propose a reasonable stability analysis method for loess slopes with a rising groundwater level.

Thus, this study adopted the sequentially coupled method of seepage-softening-stability in the stability analysis of a loess slope with a rising groundwater level. First of all, it is pointed out that water is the main controlling factor of the attenuation of strength parameters. Then, the relationship among the deformation parameters, the strength parameters, and the volumetric water content was established, namely, the water-induced structural deterioration equation. Finally, based on the vector sum analysis method of slope stability, the water-induced structural deterioration equation was introduced to study the progressive failure process of the loess slope and reveal the progressive failure mechanism of the loess slope.

\section{Methods}

2.1. Water-Induced Structural Deterioration Equation. The curves of unit weight, deformation modulus, Poisson's ratio, cohesion, internal friction angle, and volumetric water content could be obtained from experimental data $[5,6]$, as shown in Figure 1. The unit weight and Poisson's ratio of the soil mass increased with increasing volumetric water content. By contrast, the deformation modulus and cohesion of the soil mass decreased with increasing volumetric water content. The friction angle of the soil mass remained nearly unchanged with increasing volumetric water content. The expressions between unit weight, deformation modulus, Poisson's ratio, cohesion, internal friction angle, and volumetric water content were obtained by quartic polynomial fitting as follows:

$$
\begin{aligned}
\gamma= & 14.03+13.99 \theta_{\mathrm{w}}-28.74 \theta_{\mathrm{w}}^{2}+64.97 \theta_{\mathrm{w}}^{3}-22.51 \theta_{\mathrm{w}}^{4} \\
E_{0}= & 16.65-8.65 \theta_{\mathrm{w}}-255.63 \theta_{\mathrm{w}}^{2}+701.10 \theta_{\mathrm{w}}^{3}-545.62 \theta_{\mathrm{w}}^{4} \\
\mu= & 0.23+0.27 \theta_{\mathrm{w}}+0.057 \theta_{\mathrm{w}}^{2}+0.053 \theta_{\mathrm{w}}^{3}-0.45 \theta_{\mathrm{w}}^{4} \\
c= & 300197.66-1168900 \theta_{\mathrm{w}}+382494.39 \theta_{\mathrm{w}}^{2}+2866070 \theta_{\mathrm{w}}^{3} \\
& -2509420 \theta_{\mathrm{w}}^{4}, \\
\varphi= & 28^{\circ}
\end{aligned}
$$

where $\gamma$ is the total unit weight $\left(\mathrm{kN} / \mathrm{m}^{3}\right), E_{0}$ is the deformation modulus ( $\mathrm{MPa}), \mu$ is Poisson's ratio, $c$ is the cohesion $(\mathrm{Pa}), \varphi$ is the internal friction angle $\left(^{\circ}\right)$, and $\theta_{\mathrm{w}}$ is the volumetric water content.

2.2. Vector Sum Analysis Method of Loess Slope Stability. First, the hydraulic gradient, pore pressure, and volumetric water content of four Gaussian points of each element were obtained through unsaturated and transient seepage analysis. Then, the arithmetic average of the hydraulic gradient of the four Gaussian points was regarded as the average hydraulic gradient of each element, and the average hydraulic gradient was converted into the seepage force of each element. According to the water-induced structural deterioration equation, the temporal-spatial distributions of the total unit weight, elastic modulus, Poisson's ratio, cohesion, and internal friction angle of the slope were obtained according to the spatial evolution laws of volumetric water content under rising groundwater level conditions. The distribution laws of effective unit weight were obtained according to the distribution laws of total unit weight and pore pressure. On the basis of these distribution laws, the change process of the slope safety factor was determined by the vector sum analysis method in the framework of the body force method $[11,12]$. Slip-line field theory was applied for searching the critical slip surface [13]. Thus, the vector sum analysis method of loess slope stability was proposed. The concrete realization process is as follows.

(1) The software GeoStudio was used to analyze the transient seepage of an unsaturated loess slope under rising groundwater level conditions [14]. Then, the hydraulic gradient, pore pressure, and volumetric water content of the four Gaussian points of each element were extracted.

(2) The temporal-spatial distribution of the total unit weight, elastic modulus, Poisson's ratio, cohesion, and internal friction angle of the slope were 


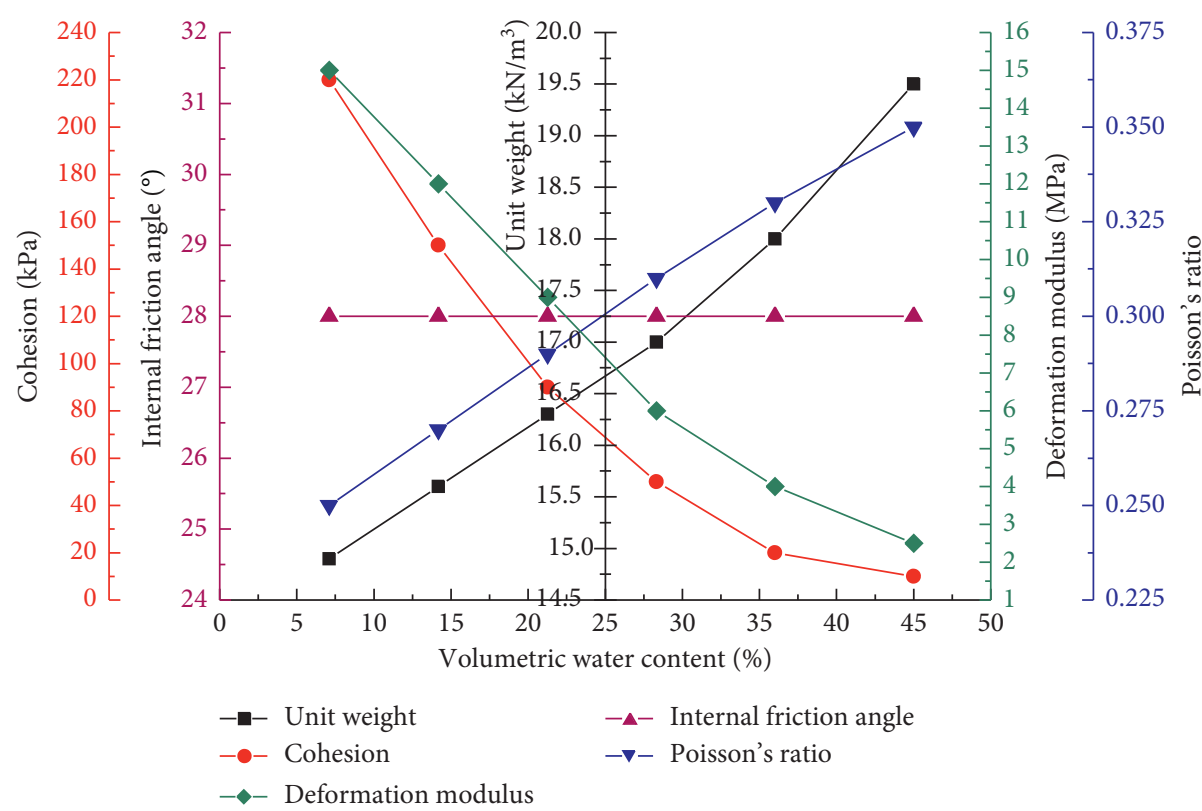

FIGURE 1: Relationship between unit weight, deformation modulus, Poisson's ratio, cohesion, internal friction angle, and volumetric water content.

calculated using the water-induced structural deterioration equation, which was formulated on the basis of the temporal-spatial evolution laws of volumetric water content. The distribution laws of effective unit weight were obtained according to the distribution laws of total unit weight and pore pressure.

(3) On the basis of the distribution laws of effective unit weight, elastic modulus, Poisson's ratio, internal friction angle, cohesion, and seepage force at each moment, stress-strain analysis was conducted at each moment by the body force method.

(4) Slip-line field theory was applied for searching the critical slip surface.

(5) The stress states of each point on the slip surface and the strength parameters of each microsegment could be determined by the stress interpolation at any point on the sliding surface and the identification of the element number. The function of stress interpolation can be expressed as follows:

$$
\sigma_{i j}=\frac{\sum_{k=1}^{n_{\mathrm{g}}} w_{k} \sigma_{i j}^{k}}{\sum_{k=1}^{n_{\mathrm{g}}} w_{k}},
$$

here, $n_{\mathrm{g}}$ is the number of Gaussian points of the element, $\sigma_{i j}^{k}$ is the stress of the $k$ th Gaussian point, and $w_{k}$ is the weight factor, which can be expressed as follows:

$$
w_{k}= \begin{cases}r_{k}^{-2}, & r_{k} \neq 0, \\ \infty, & r_{k}=0,\end{cases}
$$

here, $r_{k}$ is the distance from the point to be solved to the $k$ th Gaussian point. In view of the convexity of the yield surface, the stress point calculated by equation (6) must be within the yield surface. A stress point that is beyond the yield surface can be adjusted to the yield surface by using the method proposed by Zheng et al. [13].

(6) The stress states at each point on the sliding surface, which are shown in Figure 2, were converted into normal and shear stresses. The stress transformation formulas are expressed in equations (8) and (9). Then, the vector sum of the driving slip force and the antisliding force can be calculated.

$$
\begin{aligned}
& \sigma_{n}=l^{2} \sigma_{x}+m^{2} \sigma_{y}+2 l m \tau_{x y}, \\
& \sigma_{\tau}=\operatorname{lm}\left(\sigma_{x}-\sigma_{y}\right)+\left(m^{2}-l^{2}\right) \tau_{x y},
\end{aligned}
$$

here, $\sigma_{n}$ and $\sigma_{\tau}$ are the normal and tangential stresses, respectively, at any point on the slip surface. $\sigma_{x}, \sigma_{y}$, and $\tau_{x y}$ are the $x$-direction normal, $y$-direction normal, and shear stresses, respectively, at any point on the slip surface. $l=\cos (n, x)$ and $m=$ $\cos (n, y)$ are the outer normal direction cosines at any point on the slip surface.

(7) The safety factor of the vector sum analysis method was defined as the ratio of the projection of the total antisliding force vector to the total driving slip force vector on the potential sliding direction [15-17]. According to this definition, the total driving slip force vector, the potential sliding direction, and the total antisliding force vector were calculated. In Figure 3, point A represents any point on the slip surface; $S$ is the position of the slip surface; $\mathbf{d}$ is the potential sliding direction of the slope; $\theta$ is the angle 


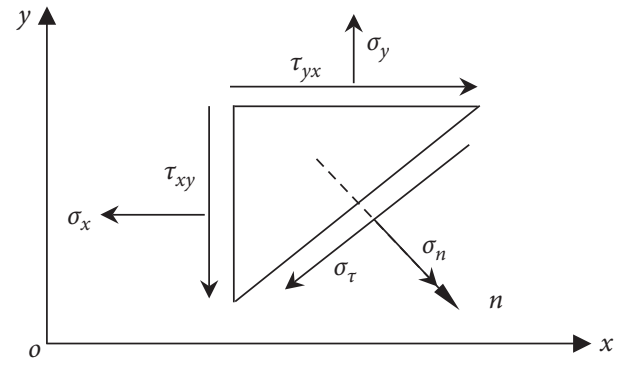

Figure 2: Normal and shear stresses on an inclined plane at a point in a soil.

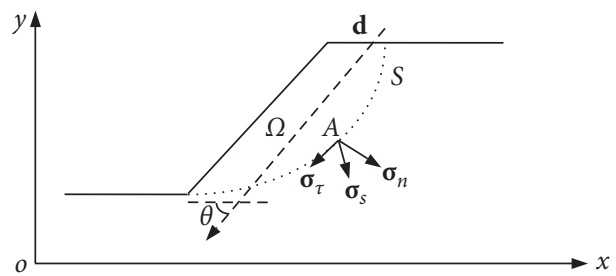

FIgURE 3: Safety factor calculated by the two-dimensional vector sum analysis method.

between the potential sliding direction and the horizontal direction; and $\sigma_{s}, \boldsymbol{\sigma}_{\tau}^{\prime}$, and $\boldsymbol{\sigma}_{s}^{\prime}$ are the driving slip, antisliding shear, and antisliding stresses, respectively, at any point on the slip surface. The other parameters are the same as those above.
The total driving slip force vector can be expressed as

$$
\int_{s} \boldsymbol{\sigma}_{s} \mathrm{~d} s=\int_{s} \boldsymbol{\sigma}_{\tau} \mathrm{d} s+\int_{s} \boldsymbol{\sigma}_{n} \mathrm{~d} s .
$$

The total antisliding shear force vector can be expressed as

$$
\int_{s} \boldsymbol{\sigma}_{\tau}^{\prime} \mathrm{d} s=\int_{s}\left[-\left(c\left(\theta_{\mathrm{w}}\right)-\sigma_{n} \tan \left[\varphi\left(\theta_{\mathrm{w}}\right)\right]\right) \frac{\boldsymbol{\sigma}_{\tau}}{\left\|\boldsymbol{\sigma}_{\tau}\right\|}\right] \mathrm{d} s .
$$

This formula shows that the fundamental difference between the proposed method and the traditional vector sum analysis method is that in the proposed method, the strength parameters change with the volumetric water content when the antisliding shear force is solved. Given that the strength parameters displayed temporal-spatial distribution laws as the groundwater level rose, the temporalspatial distribution laws of the strength parameters should be introduced into the traditional vector sum analysis method. Thus, the method proposed in this paper was formed.

The total antisliding force vector can be expressed as

$$
\int_{s} \boldsymbol{\sigma}_{s}^{\prime} \mathrm{d} s=\int_{s} \boldsymbol{\sigma}_{\tau}^{\prime} \mathrm{d} s-\int_{s} \boldsymbol{\sigma}_{n} \mathrm{~d} s .
$$

Finally, the total antisliding force vector and the driving slip force vector were projected separately along the potential sliding direction. Then, the safety factor of vector sum analysis method was obtained using the following equation:

$$
F_{s}=\frac{\int_{s}\left[\boldsymbol{\sigma}_{s}^{\prime} \cdot(-\mathbf{d})\right] \mathrm{d} s}{\int_{s}\left[\boldsymbol{\sigma}_{s} \cdot \mathbf{d}\right] \mathrm{d} s}=\frac{\int_{s}\left[\left(-\left(c\left(\theta_{\mathrm{w}}\right)-\sigma_{n} \tan \left[\varphi\left(\theta_{\mathrm{w}}\right)\right]\right)\left(\left(\boldsymbol{\sigma}_{\tau} /\left\|\boldsymbol{\sigma}_{\tau}\right\|\right)-\boldsymbol{\sigma}_{n}\right)\right) \cdot(-\mathbf{d})\right] \mathrm{d} s}{\int_{s}\left[\left(\boldsymbol{\sigma}_{\tau}+\boldsymbol{\sigma}_{n}\right) \cdot \mathbf{d}\right] \mathrm{d} s} .
$$

Here, the opposite direction of the total antisliding shear force vector was used as the potential sliding direction [15]. The expression of the potential sliding direction can be written as

$$
\mathbf{d}=\frac{\int_{s}\left[\left(c\left(\theta_{\mathrm{w}}\right)-\sigma_{n} \tan \left[\varphi\left(\theta_{\mathrm{w}}\right)\right]\right)\left(\boldsymbol{\sigma}_{\tau} /\left\|\boldsymbol{\sigma}_{\tau}\right\|\right)\right] \mathrm{d} s}{\left\|\int_{s}\left[\left(c\left(\theta_{\mathrm{w}}\right)-\sigma_{n} \tan \left[\varphi\left(\theta_{\mathrm{w}}\right)\right]\right)\left(\boldsymbol{\sigma}_{\tau} /\left\|\boldsymbol{\sigma}_{\tau}\right\|\right)\right] \mathrm{d} s\right\|}
$$

2.3. Limit Equilibrium Method of Loess Slope Stability. To verify the reliability of vector sum analysis method of loess slope stability proposed in this paper, the limit equilibrium method of loess slope stability was conducted. The specific principle of the latter is as follows.

The spatial distributions of pore pressure and volumetric water content can be obtained through unsaturated and transient seepage analysis. However, the limit equilibrium method of slope stability is concerned with the pore pressure and strength parameters at the base of a slice. Thus, a spline interpolation technique was adopted to determine the pore pressure and strength parameters at the base of a slice when these parameters were defined at discrete points. Suppose we know a set of values, $p_{i}$, at $n$ given points $\left(\left(x_{i}, y_{i}\right)\right.$ with $i=1,2, \ldots, n)$, and we want to estimate the value of $p$ at some other points, $p(x, y)$. The expression of the spline interpolation function can be given as

$$
p(x, y)=a_{1}+a_{2} x+a_{3} y+\sum_{i=1}^{n} \lambda_{i} K\left(h_{m i}\right)
$$

here, $h_{m i}$ is the distance between point $m$ and point $i$, where $h_{m i}=\sqrt{\left(x_{m}-x_{i}\right)^{2}+\left(y_{m}-y_{i}\right)^{2}} . \quad K(h)=\delta(0)+h^{2} \log h$, where $\delta(0)$ is the nugget effect, which is typically assumed to be zero. Matrix $K$ was defined, where $k_{i j}=h_{i j}^{2} \log h_{i j}$. $\lambda_{1}, \lambda_{2}, \ldots, \lambda_{n}, a_{1}, a_{2}, a_{3}$ are the coefficients to be solved. $\lambda=\left[\lambda_{1}, \lambda_{2}, \ldots, \lambda_{n}\right]^{T}$ and $a=\left[a_{1}, a_{2}, a_{3}\right]^{T}$ were defined, where $\sum_{i=1}^{n} \lambda_{i}=0, \sum_{i=1}^{n} \lambda_{i} x_{i}=0$, and $\sum_{i=1}^{n} \lambda_{i} y_{i}=0$. Matrix $T$ was defined with three rows and $n$ columns and expressed as

$$
T=\left[\begin{array}{cccc}
1 & 1 & \cdots & 1 \\
x_{1} & x_{2} & \cdots & x_{n} \\
y_{1} & y_{2} & \cdots & y_{n}
\end{array}\right],
$$

$p=\left[p_{1}, p_{2}, \ldots, p_{n}\right]^{T}$ was defined. The coefficients $\left(\lambda_{1}, \lambda_{2}, \ldots, \lambda_{n}, a_{1}, a_{2}, a_{3}\right)$ are the solution of the following set of linear equations: 


$$
\left[\begin{array}{cc}
K & T^{T} \\
T & 0
\end{array}\right]\left[\begin{array}{l}
\lambda \\
a
\end{array}\right]=\left[\begin{array}{l}
p \\
0
\end{array}\right] .
$$

By solving this system of linear equations, all the coefficients $\left(\lambda_{1}, \lambda_{2}, \ldots, \lambda_{n}, a_{1}, a_{2}, a_{3}\right)$ can be obtained. By the substitution of these coefficients into equation (15), the pore pressure and strength parameters at any point can be determined.

In this way, the distribution laws of pore pressure and volumetric water content under rising groundwater level conditions could be obtained through unsaturated and transient seepage analysis. The distribution laws of the total unit weight, internal friction angle, and cohesion of slope under rising groundwater level conditions were obtained by means of the water-induced structural deterioration equation. On the basis of the distribution laws of pore pressure, total unit weight, internal friction angle, and cohesion at each moment, the change process of the slope safety factor under rising groundwater level conditions was determined by the limit equilibrium method [18-21]. A method of specifying the range of entry and exit of the slope was adopted to search for the critical slip surface [22]. Thus, the limit equilibrium method of loess slope stability was conducted.

\section{Results}

The calculated model originated from a loess slope on the border of the White Deer Plain in the eastern suburbs of $\mathrm{Xi}$ 'an, as shown in Figure 4. The total width of the model was $72.7 \mathrm{~m}$, and the total height was $40 \mathrm{~m}$. The dotted line in the figure denotes the position of the initial groundwater level. The model was divided into 13608 nodes and 13360 elements. The bottom boundary condition was pinned, and rollers were used along the vertical extents of the model. The slope surface was the potential seepage face. The right side of the model was the head boundary which changed from $28 \mathrm{~m}$ to $38 \mathrm{~m}$ with the change in groundwater level due to the leakage of the pond.

The soil-water characteristic curve and hydraulic conductivity function in the $x$-direction were used in the unsaturated and transient seepage analysis, as shown in Figure 5 . The permeability coefficient in the $y$-direction was five times greater than that in the $x$-direction. The mechanical parameters used in the stress-strain analysis are shown in equations (1)-(5) in Section 2.1. According to engineering experience, the elastic modulus was regarded to be 10 times greater than the deformation modulus.

3.1. Seepage Analysis. Figure 6 shows the positions of the phreatic line at different times under rising groundwater level conditions. The position of the phreatic line increased with the increasing groundwater level. The rising rate of the phreatic line at the right boundary of slope was nearly unchanged from the initial time to day 365 , whereas the water level at the right boundary of the slope stopped increasing beyond this date. These were consistent with the hydraulic boundary condition at the right boundary of the slope. From day 365 to day 730 , the position of the phreatic line changed only minimally and mainly displayed the rise of the seepage exit and the bulge in the middle of the phreatic line.

Figures 7 and 8 depict the distribution laws of pore pressure and volumetric water content, respectively, under rising groundwater level conditions. The distribution laws of pore pressure agreed well with those of volumetric water content. At the initial time, the ranges of pore pressure and volumetric water content were $[-150,250] \mathrm{kPa}$ and $[0.19$, $0.45]$, respectively. The range of pore pressure became $[-150$, $300] \mathrm{kPa}$ on day 180 and $[-150,350] \mathrm{kPa}$ on day 365 . The range of pore pressure did not change between days 365 and 730. The isolines of pore pressure and volumetric water content above the groundwater level under rising groundwater level conditions became increasingly dense.

3.2. Temporal-Spatial Evolution Laws of the Deformation and Strength Parameters. The temporal-spatial distribution laws of total unit weight, elastic modulus, Poisson's ratio, and cohesion are shown in Figures 9-12. The internal friction angle remained constant under rising groundwater level conditions. Thus, its temporal-spatial distribution laws were not extracted. The distribution laws of total unit weight, elastic modulus, Poisson's ratio, and cohesion were the same and consistent with the distribution laws of volumetric water content. The range of the deformation and strength parameters were broadened in the saturated region, and the isolines of the deformation and strength parameters became increasingly dense in the unsaturated region, suggesting that the deformation and strength parameters were degraded to a certain extent.

\subsection{Results Obtained by Limit Equilibrium Method of Loess} Slope Stability. The variation process of the minimum safety factor was determined by Spencer's and MorgensternPrice's methods, as shown in Figure 13. The minimum safety factor of the slope gradually decreased with the rising groundwater level. The minimum safety factors determined by the two methods had an insignificant difference, and the maximum error was 0.031 .

The distribution laws of pore pressure and cohesion on each slip surface were determined by Spencer's method, as shown in Figures 14 and 15, respectively. With the rising groundwater level, the pore pressure on the critical slip surface increased, whereas the cohesion decreased. The distribution laws of pore pressure on the critical slip surface at each moment were always consistent. The entire slip surface was basically in the unsaturated region at the initial time. The saturated region of the slip surface became increasingly large with the rising groundwater level and remained stable after 635 days. The distribution laws of cohesion on the critical slip surface at each moment were the same. The cohesion on a small part of the critical slip surface reached the minimum value, and the distribution range of cohesion on the entire slip surface was wide at the initial time. The region of the minimum cohesion on the critical slip surface increased with the rising groundwater level, and the distribution range of cohesion on the entire slip surface gradually narrowed. The distribution laws of cohesion were nearly stable after 635 days. 


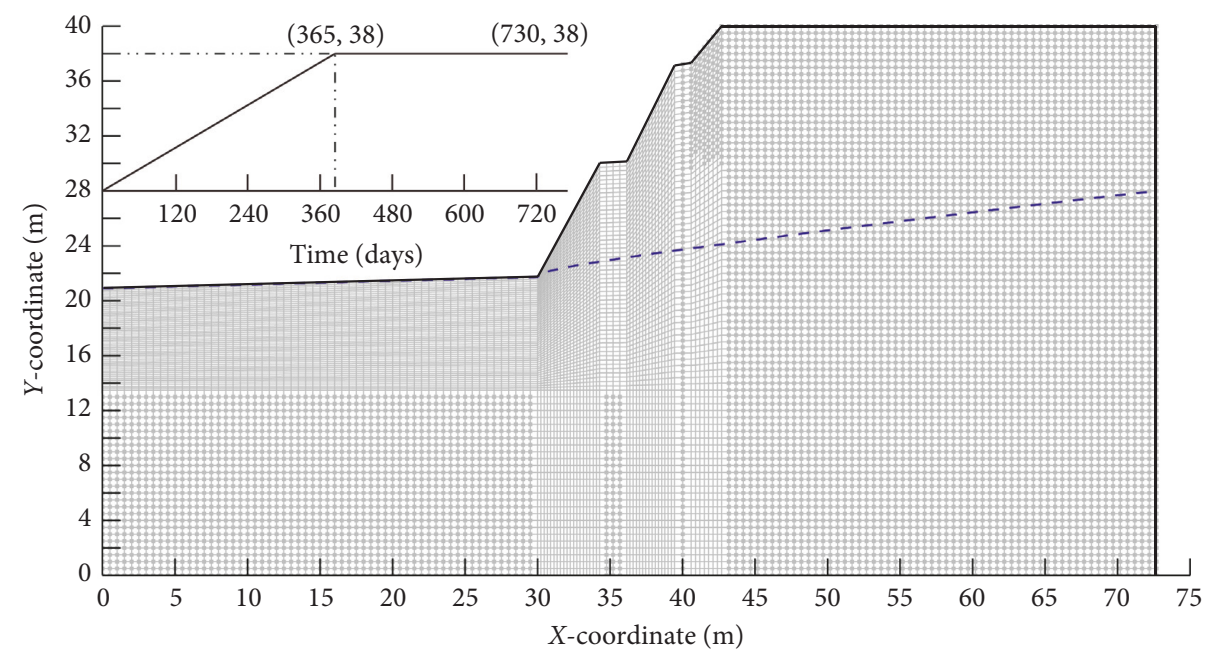

FIGURE 4: Mesh of the calculation model and the head boundary condition at the right side of the model.

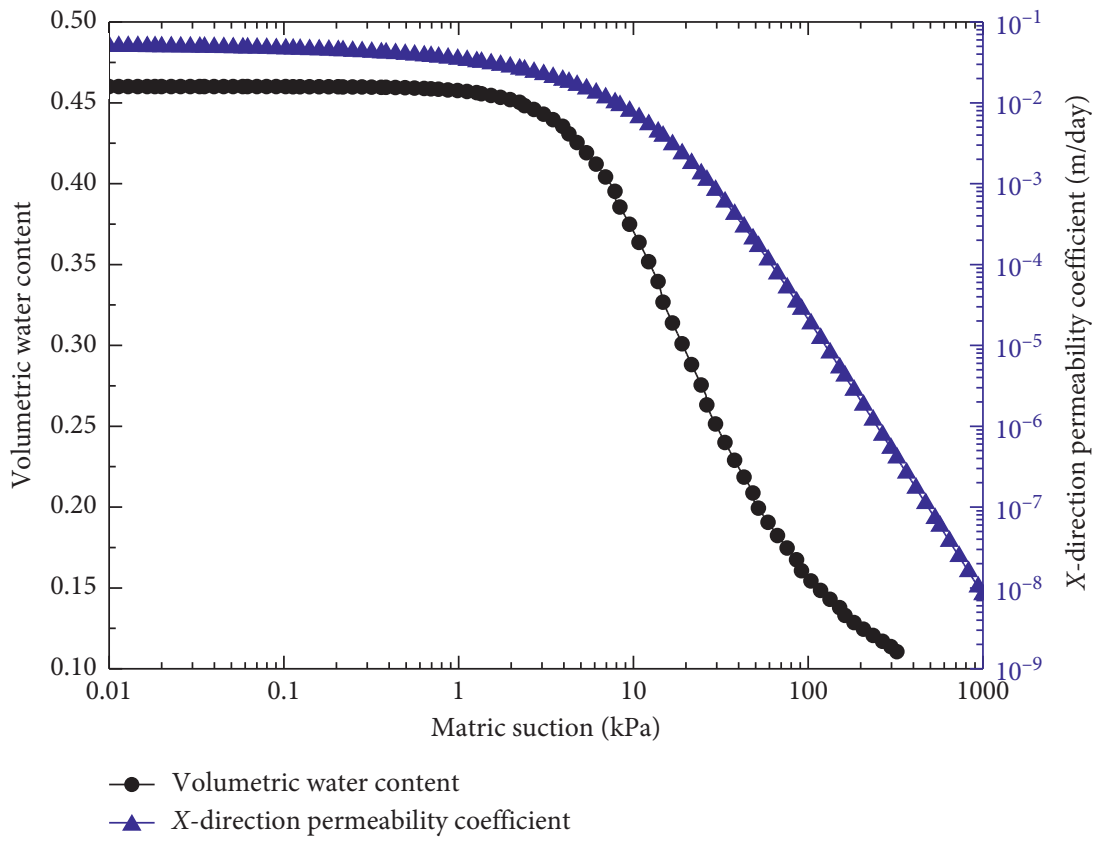

FIgURE 5: Soil-water characteristic curve and hydraulic conductivity function in the $x$-direction.

3.4. Results Obtained by Vector Sum Analysis Method of Loess Slope Stability. The slip surfaces were determined by different methods at day 635, which was the time of slope instability, as shown in Figure 16. The slip surface obtained by slip-line field theory was close to that obtained by Spencer's method and was located between the slip surfaces obtained by Spencer's and Morgenstern-Price's methods, implying that slip-line field theory is suitable for searching the slip surface. The slip surface obtained by the maximum equivalent plastic strain [23] agreed well with those acquired by the three other methods in the lower part but significantly deviated in the upper part.

Figure 17 shows the change process of the safety factors determined by the vector sum analysis method corresponding to the two different slip directions [24]. The safety factor of the slope gradually decreased with the rising groundwater level, and the slope was unstable at day 635, which was consistent with the actual situation. The difference of the slope safety factor corresponding to two different slip directions was insignificant, and the maximum error was 0.0495 .

Figures 18 and 19 depict the distribution laws of pore pressure and cohesion, respectively, on the final slip surface at different times. The pore pressure on the final slip surface increased with the rising groundwater level, whereas the cohesion decreased. The distribution laws of pore pressure on the final slip surface at different times were always consistent and displayed the trend of initially increasing and subsequently decreasing with the $x$-coordinate. The entire slip surface was basically in the unsaturated region at the 


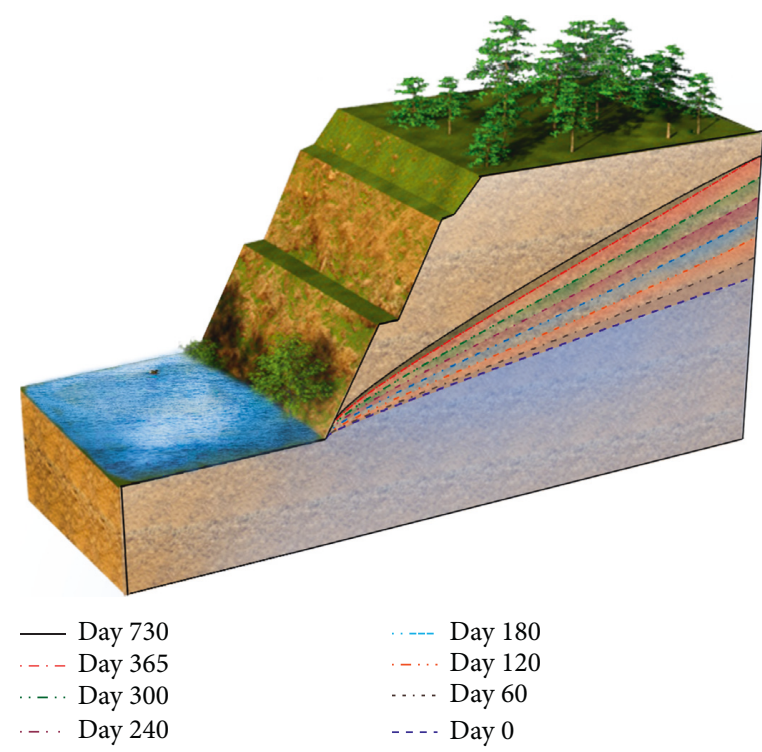

FIgURe 6: Positions of the phreatic line at different times under rising groundwater level conditions.

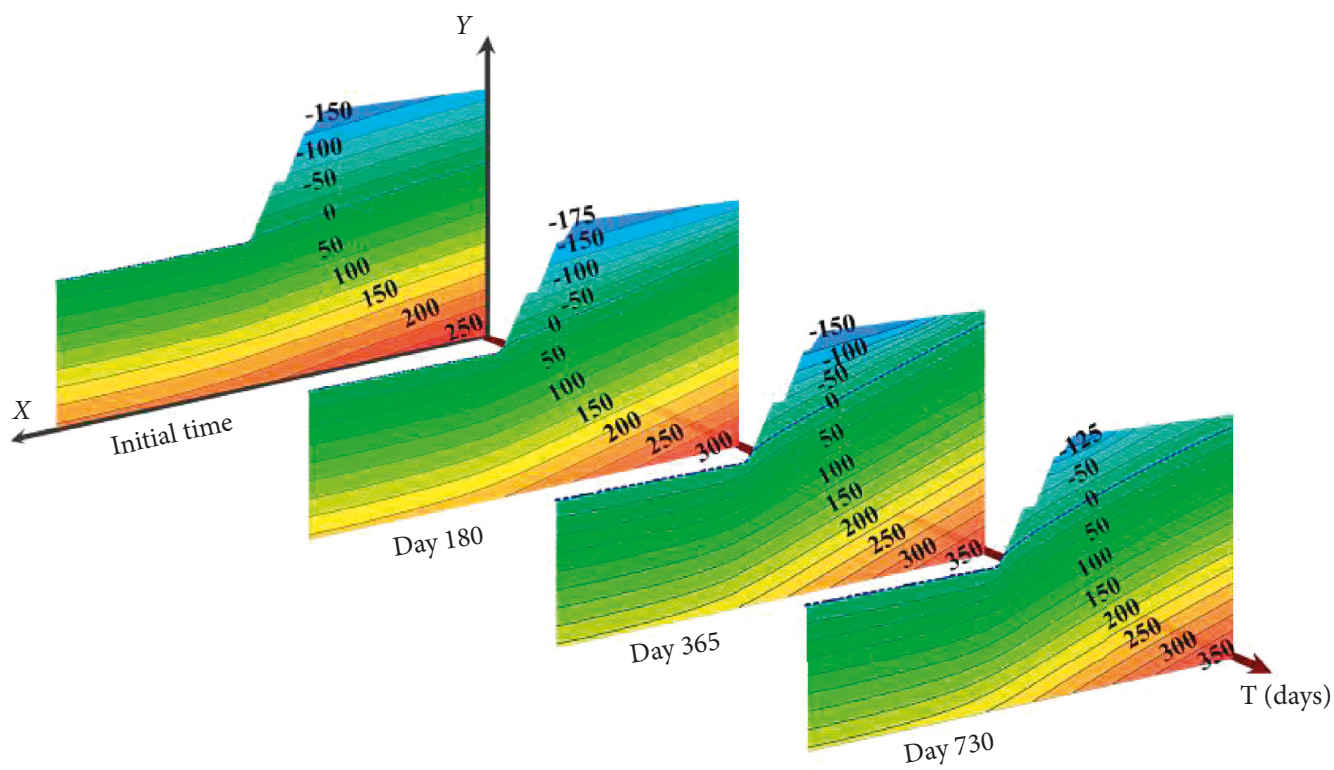

FIGURE 7: Distribution laws of pore pressure under rising groundwater level condition.

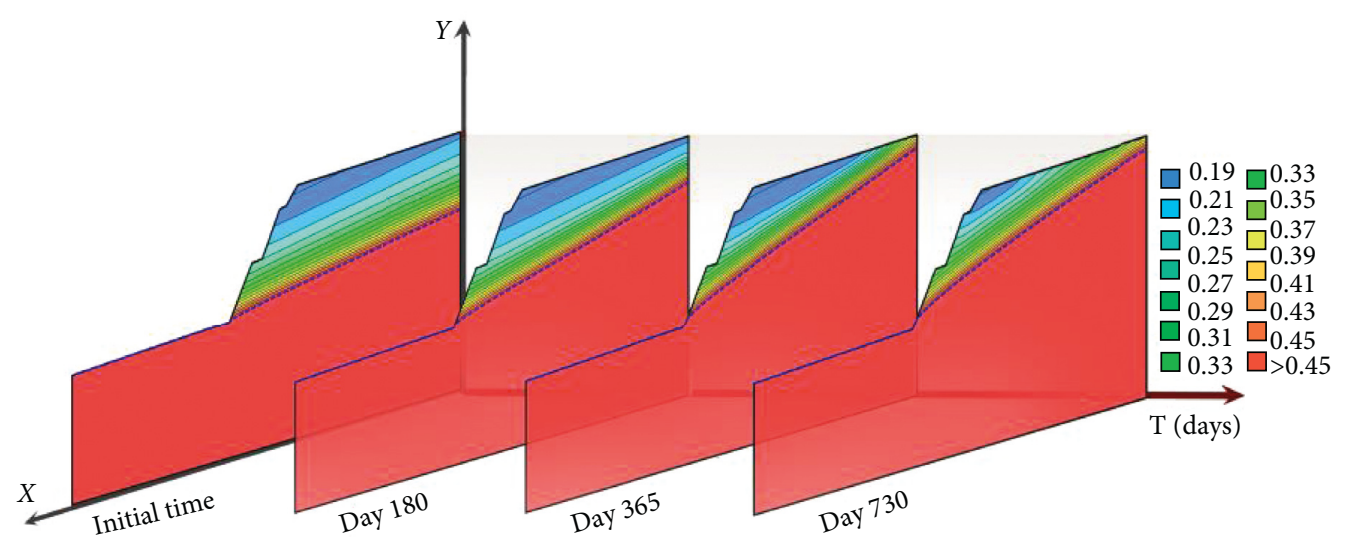

FigURE 8: Distribution laws of volumetric water content under rising groundwater level conditions. 


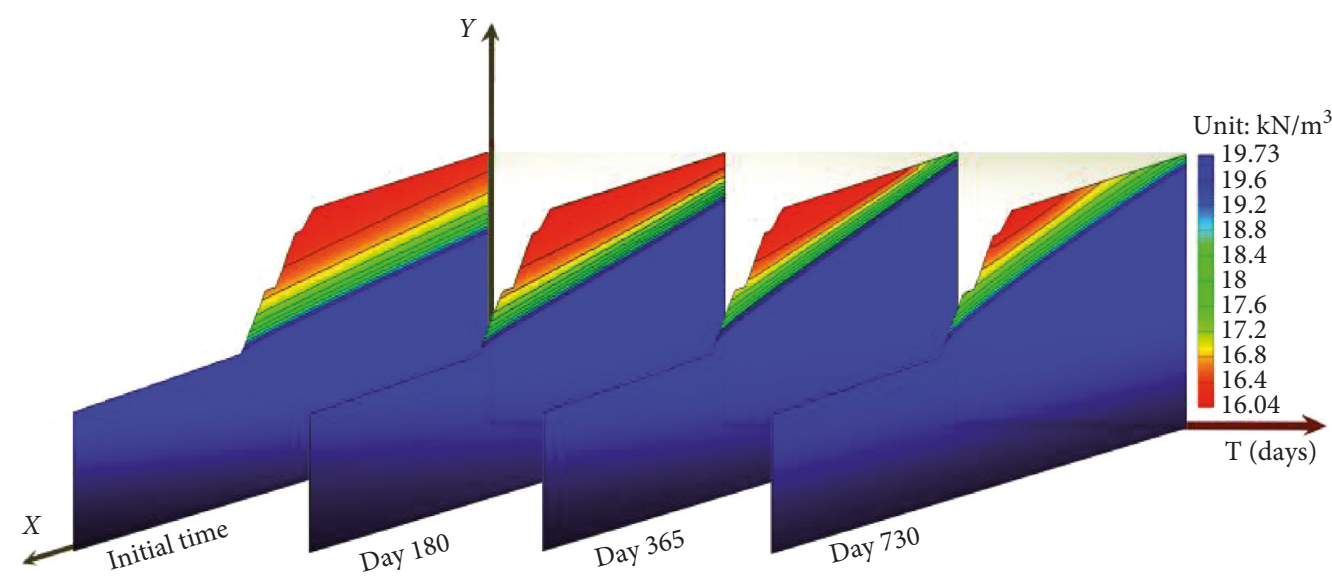

FIGURE 9: Distribution laws of total unit weight under rising groundwater level conditions.

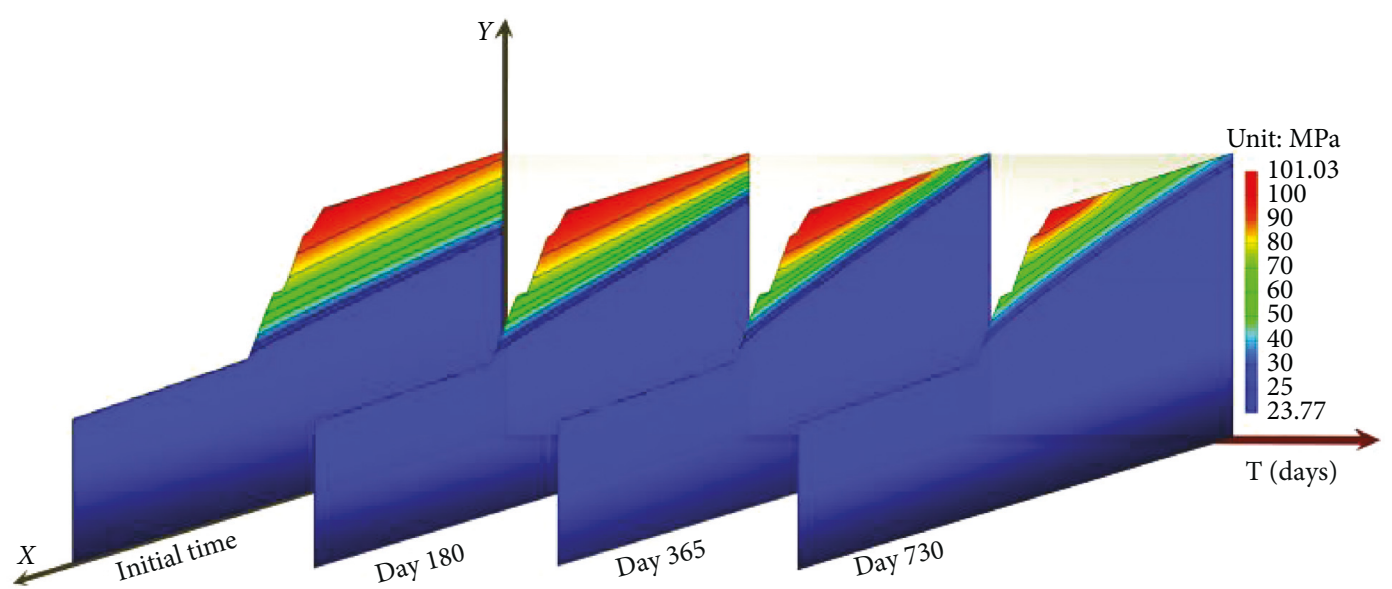

FIgURE 10: Distribution laws of elastic modulus under rising groundwater level conditions.

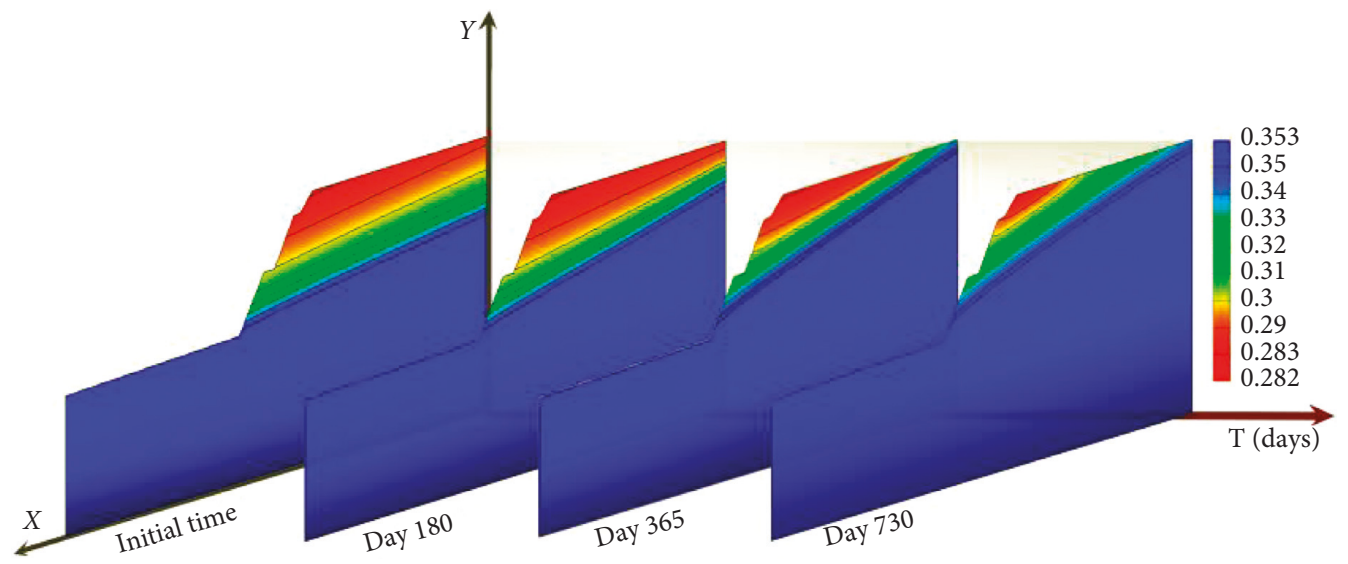

FIgURE 11: Distribution laws of Poisson's ratio under rising groundwater level conditions.

initial time. The saturated region of the slip surface became increasingly large with the rising groundwater level and remained stable after 635 days. The distribution laws of cohesion on the final slip surface at different times were the same and showed the trend of initially being constant and subsequently increasing from the exit to the entry of the slip surface. The cohesion on a small part of the critical slip surface reached the minimum value, and the distribution range of cohesion on the entire slip surface was wide at the initial time. The region of the minimum cohesion on the final slip surface increased with the rising groundwater level, and the distribution range of cohesion on the final slip 


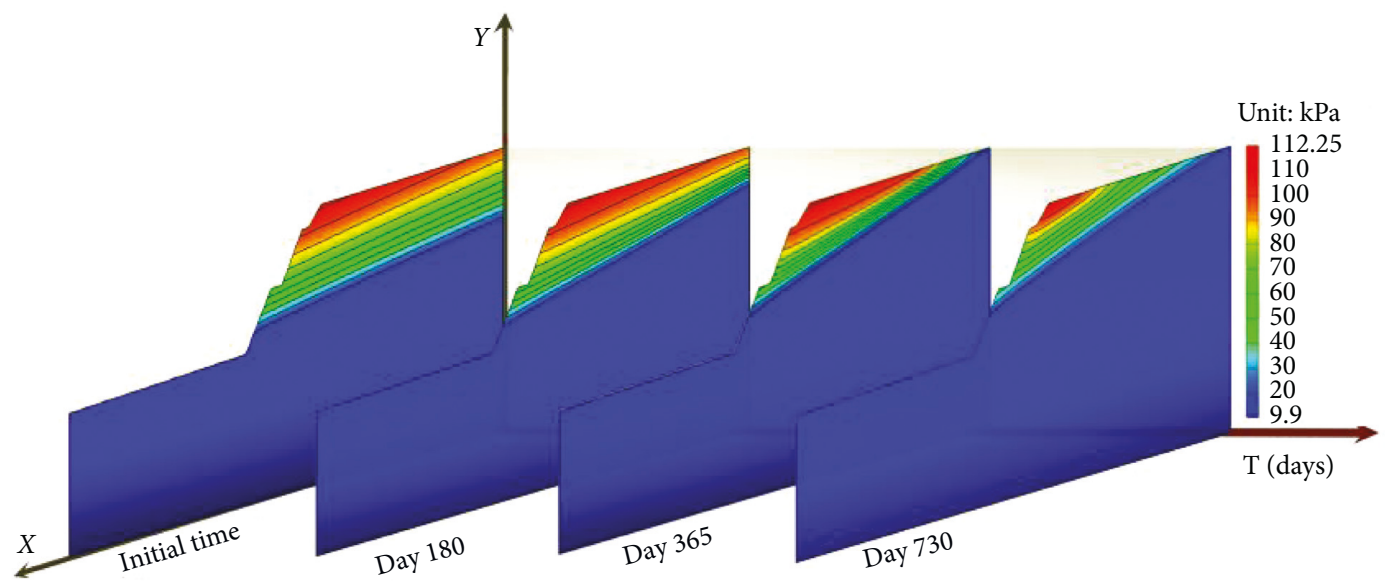

FIGURE 12: Distribution laws of cohesion under rising groundwater level conditions.

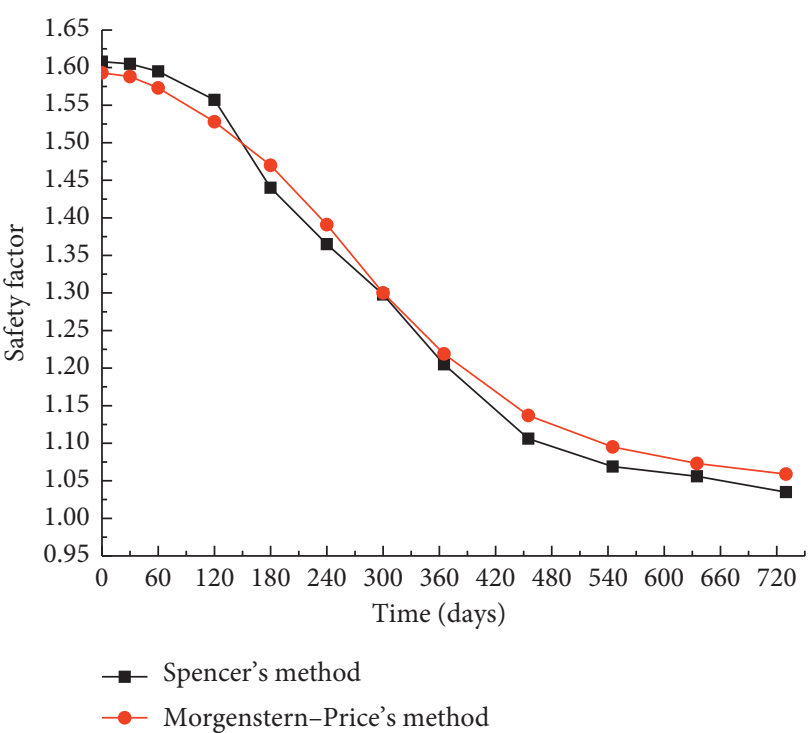

FIgURE 13: Variation process of the minimum safety factor determined by Spencer's and Morgenstern-Price's methods.

surface gradually narrowed. The distribution laws of cohesion were nearly stable after 635 days. These laws were consistent with the corresponding results determined by the limit equilibrium method of loess slope stability.

Figure 20 shows the slope safety factors determined by different methods under rising groundwater level conditions. The slope safety factors decreased with the rising groundwater level. The minimum safety factors determined by Spencer's method were greater than the safety factors corresponding to the final slip surface determined by the other methods before day 365. The slope safety factors determined by the four different methods were close on day 455. The minimum safety factors determined by Spencer's method were between the safety factors determined by Bishop's method and those by the vector sum analysis method from day 545 to day 730 . Before day 455 , the safety factors corresponding to the final slip surface determined by Bishop's method were close to the safety factors

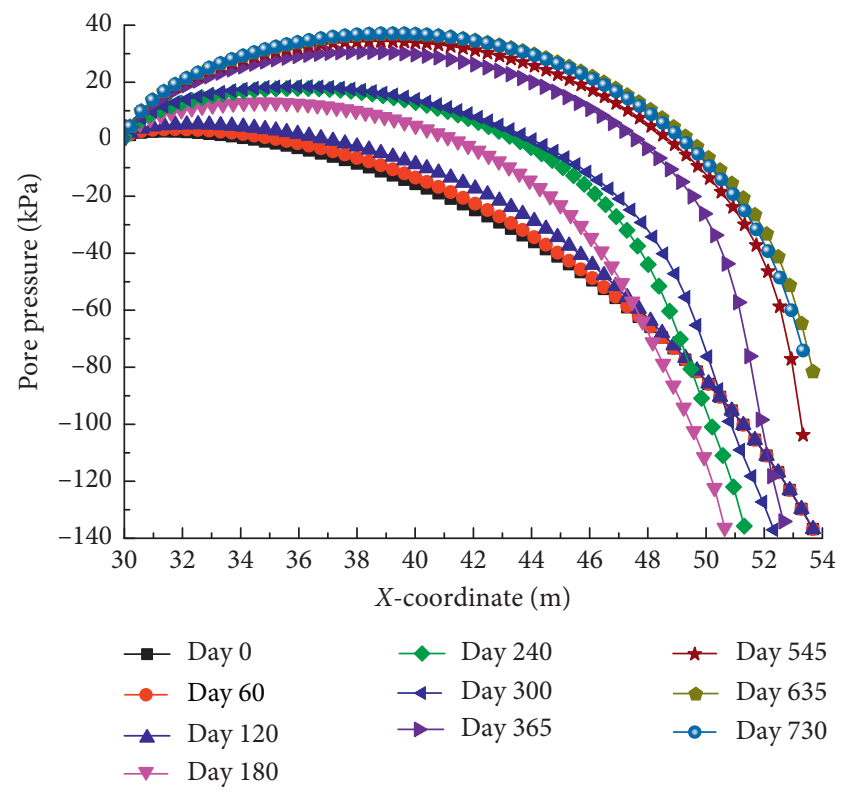

FIgURE 14: Distribution laws of pore pressure on each slip surface determined by Spencer's method.

corresponding to the final slip surface determined by plan A that the direction of the total driving shear force vector was regarded as the potential sliding direction in the vector sum analysis method, and the maximum error was 0.012 . In comparison, for the slope safety factors corresponding to the final slip surface determined by plan B that the opposite direction of the total antisliding shear force vector was considered as the potential sliding direction in the vector sum analysis method, and the maximum error was 0.0597 . After day 455, the safety factors corresponding to the final slip surface determined by Bishop's method were greater than those determined by the vector sum analysis method. However, the determination of the two different slip directions in the vector sum analysis method had only a minimal effect on the slope safety factors.

Overall, the reliability and rationality of the vector sum analysis method of loess slope stability were verified by 


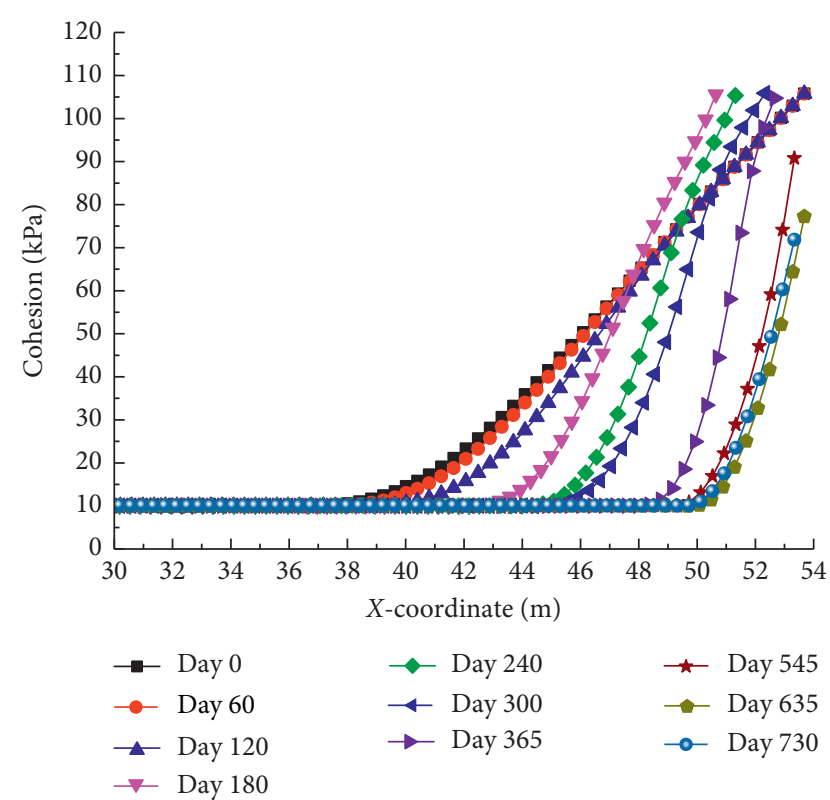

Figure 15: Distribution laws of cohesion on each slip surface determined by Spencer's method.

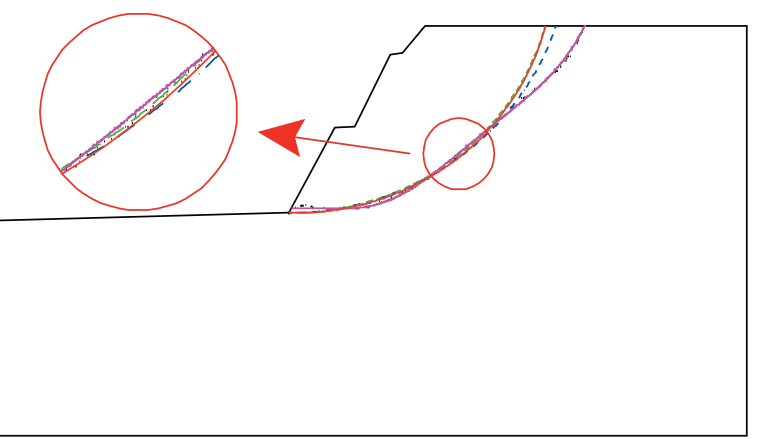

- - - Spencer's method

— Slip-line field theory

. - - - Morgenstern-Price's method

_ Maximum equivalent plastic strain (spline curve fitting)

.... ... Maximum equivalent plastic strain (a set of scatter dots)

FIGURE 16: Slip surfaces determined by different methods at day 635.

comparing the results with those obtained by the limit equilibrium method of loess slope stability.

\section{Discussion}

Taking the stability analysis of a loess slope with the rising groundwater level as an example and using the sequentially coupled method of seepage-softening-stability, this study proposed the vector sum analysis method of loess slope stability. The reliability of the vector sum analysis method of loess slope stability was verified by a comparative analysis of the calculation results obtained by the limit equilibrium method of loess slope stability. The advantages and disadvantages of the two methods are distinct.

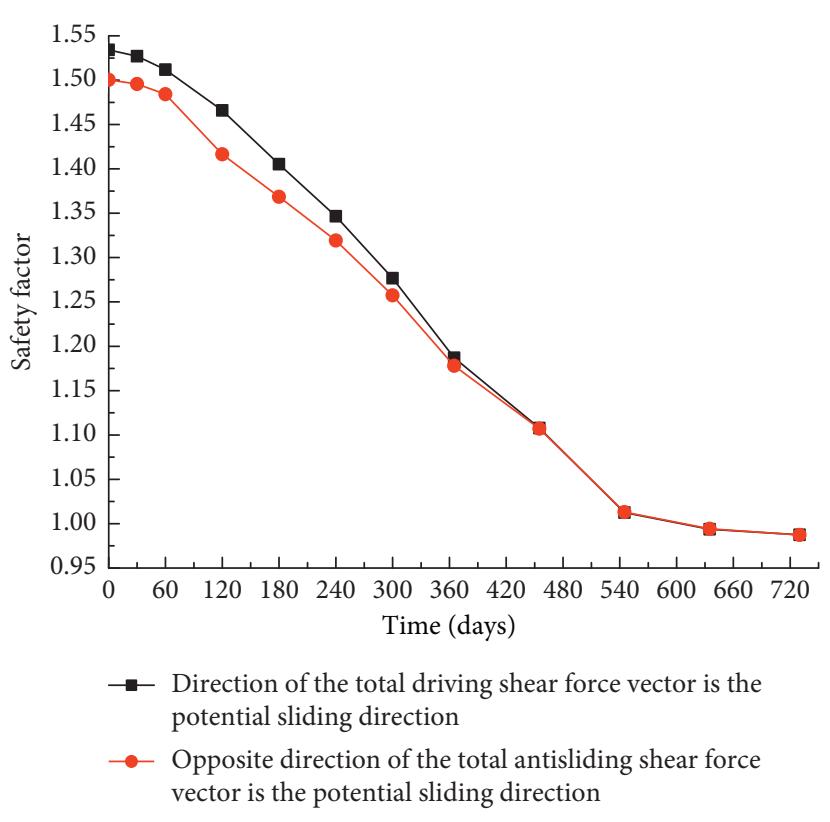

FIgURE 17: Change process of the safety factors determined by the vector sum analysis method corresponding to the two different slip directions.

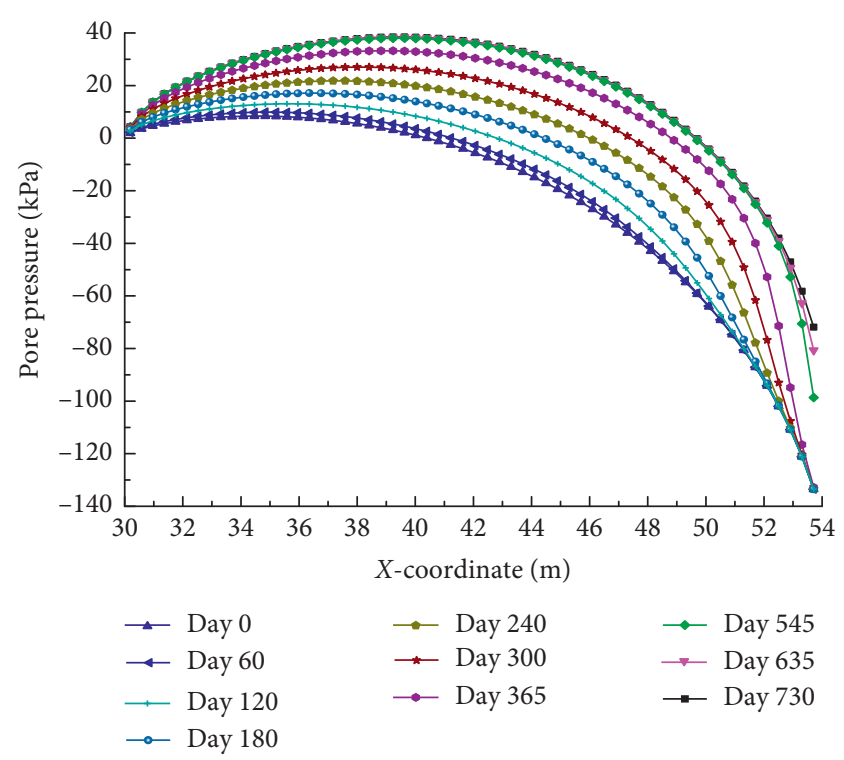

FIGURE 18: Distribution laws of pore pressure on the final slip surface at different times.

The limit equilibrium method of loess slope stability is simple and convenient, so it is widely accepted by geotechnical engineers. However, this method is difficult to take the stress-strain relationship of loess into account, and the assumption that the overall sliding surface reaches the limit equilibrium state simultaneously is not consistent with the failure process of loess slope. Last but not least, the safety factor obtained by this method is the ratio of sliding resisting force to sliding force. For a straight slip line, the physical meaning of the safety factor is clear. For a circular slip line, the safety factor is actually the ratio of the total resisting moment to the total driving moment. For a nonstraight line 


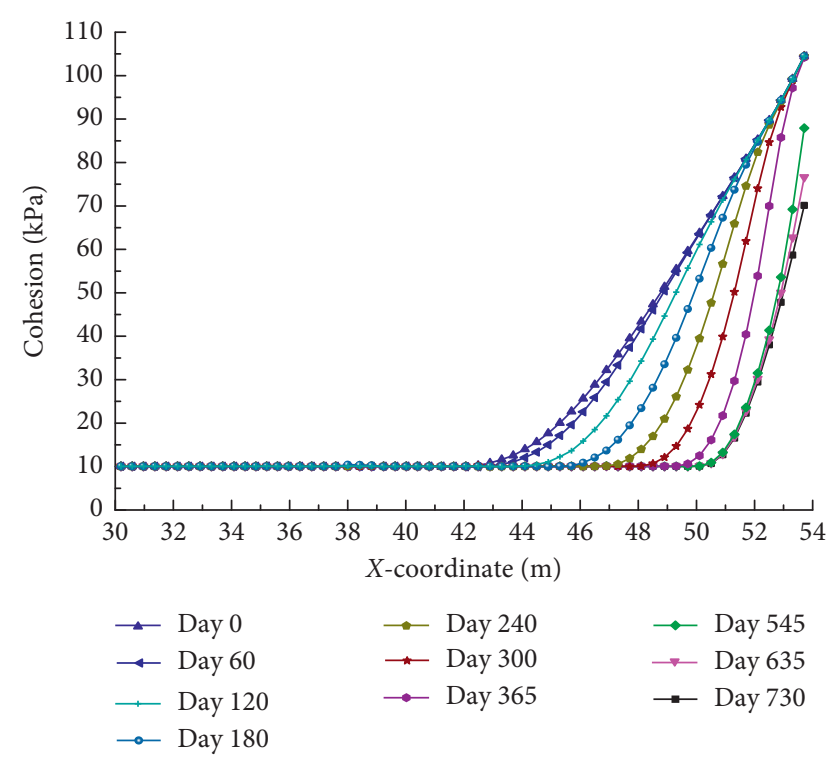

FIGURE 19: Distribution laws of cohesion on the final slip surface at different times.

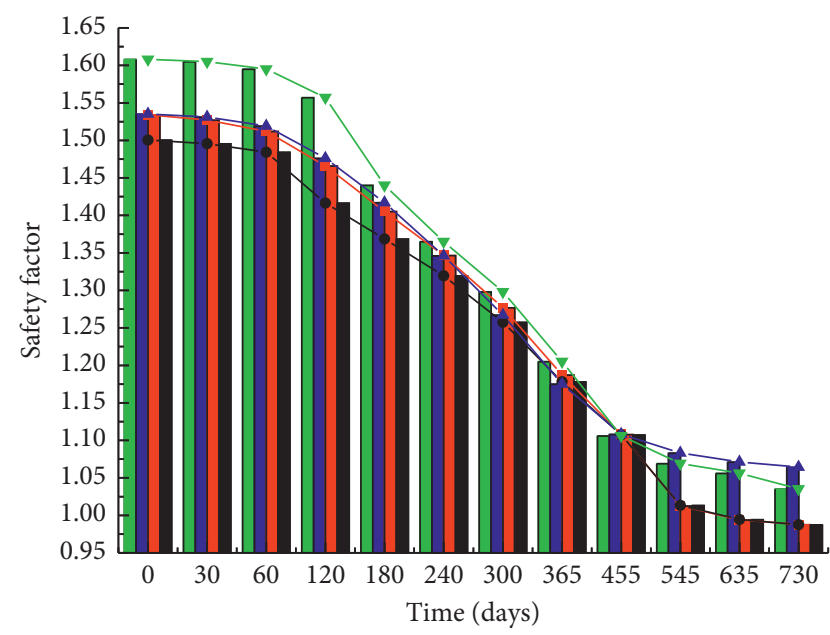

\footnotetext{
Minimum safety factor determined by Spencer's method

- Safety factor corresponding to the final slip surface determined by Bishop's method

$\square$ Safety factor corresponding to the final slip surface determined by vector sum analysis method A

- Safety factor corresponding to the final slip surface determined by vector sum analysis method B
}

FIGURE 20: Slope safety factors determined by different methods under rising groundwater level conditions.

or a noncircular slip line, however, the physical meaning of the safety factor is questioned because the integration in the definition of this safety factor is neither the summation of force vectors in space nor the summation of projections of force vectors in a fixed direction.

The vector sum analysis method of loess slope stability can take the stress-strain relationship of loess into account conveniently, and moreover, the safety factor obtained by this method has a more concrete meaning. The force is vector and the safety factor is scalar. The projection is an effective way for converting the vector into the scalar, so the safety factor obtained by this method is defined as the ratio of the projection of the total antisliding force vector to the total driving slip force vector on the potential sliding direction. Thus, this method can evaluate the loess slope stability more accurately. However, the potential sliding direction needs to be further studied.

\section{Conclusions}

(1) The position of the phreatic line rose with the rising groundwater level. The difference in the groundwater level became increasingly small after day 365 . The distribution laws of pore pressure were consistent with those of volumetric water content. The isolines of pore pressure and volumetric water content above the groundwater level under rising groundwater level conditions became increasingly dense.

(2) On the basis of the dynamic seepage field of the slope under rising groundwater level conditions, the spatial distribution of the deformation and strength parameters of the soil were adjusted according to the water-induced structural deterioration equation, and the seepage forces of the elements were constantly updated according to the hydraulic gradient of each Gaussian point. The temporal-spatial evolution laws of the deformation and strength parameters revealed that the range of the deformation and strength parameters was broadened in the saturated region, and the isolines of the deformation and strength parameters became increasingly dense in the unsaturated region, suggesting that the deformation and strength parameters were degraded to a certain extent.

(3) On the basis of the temporal-spatial distribution laws of effective unit weight, elastic modulus, Poisson's ratio, cohesion, internal friction angle, and seepage force, the vector sum analysis method of loess slope stability was proposed by the body force method. To verify this method, the limit equilibrium method of loess slope stability was conducted by the surface force method on the basis of the temporal-spatial distribution laws of total unit weight, cohesion, internal friction angle, and pore pressure.

(4) A comparison of the results obtained by the two methods revealed that the slip surface obtained by slip-line field theory was located between those determined by Spencer's and Morgenstern-Price's methods. The slope safety factors determined by Bishop's method of loess slope stability were insignificantly different from those calculated by the vector sum analysis method of loess slope stability before day 455. After this day, the determination of the two different slip directions in the vector sum analysis method had only a minimal effect on the slope safety factors. The slope became unstable on day 635 , which was consistent with the actual 
situation. The overall results verified the reliability and rationality of the vector sum analysis method of loess slope stability.

\section{Data Availability}

The data used to support the findings of this study are available from the corresponding author upon request.

\section{Conflicts of Interest}

The authors declare that they have no conflicts of interest.

\section{Acknowledgments}

This research was financially supported by the National Natural Science Foundation for Excellent Young Scientists of China (Grant no. 51722907), National Natural Science Foundation of China (Grant no. 51679199), Scientific Research Program Funded by Shaanxi Provincial Education Department (Grant no. 18JK0548), and Doctoral Scientific Research Foundation of Xi'an University of Technology (Grant no. 107-256081705). The financial support provided by these sponsors is greatly appreciated.

\section{References}

[1] D. Y. Xie and Y. C. Xing, Soil Mechanics for Loess Soils, Higher education press, Beijing, China, 2016.

[2] Y. Shi, R. Wang, H. Yuan, H. Bao, and C. Yan, "Quantitative reinforcement analysis of loess slope with anisotropy," Advances in Civil Engineering, vol. 2019, Article ID 6728101, 12 pages, 2019.

[3] C. L. Chen, S. J. Shao, and G. H. Deng, "Relationship between soil structural parameters and strength and its application in slope stability analysis," Journal of Central South University (Science and Technology), vol. 41, no. 1, pp. 328-334, 2010.

[4] C. L. Chen, S. J. Shao, and F. T. She, "Impact of structural change of soils on stability in slope excavation," Chinese Journal of Geotechnical Engineering, vol. 33, no. 12, pp. 1938-1942, 2011, in Chinese.

[5] R. J. Li, W. Zheng, J. D. Liu et al., "Evaluation of stability of structural loess slope considering initial structural parameters," Rock and Soil Mechanics, vol. 35, no. 1, pp. 143-150, 2014, in Chinese.

[6] W. Zheng, "Studies on the stability analysis techniques of the structural loess slope based on its tensile characteristic," Dissertation, Xi'an University of Technology, Xi'an, China, 2012.

[7] H. Y. Fu, L. Zeng, G. Y. Wang et al., "Stability analysis of soft rock slope under rainfall infiltration," Rock and Soil Mechanics, vol. 33, no. 8, pp. 2359-2365, 2012, in Chinese.

[8] J. R. Xie, C. Y. Zhou, and Y. Cheng, "Method of seepagesoftening analysis and disaster mechanism in soft rock slope under rainfall," Rock and Soil Mechanics, vol. 35, no. 1, pp. 197-203, 2014, in Chinese.

[9] X. R. Ge, D. X. Feng, X. R. Gu et al., "Stability and deformation analysis of complex rock foundations of several large dams and hydropower stations in China," in Proceedings of the International Workshop on Rock Foundation, pp. 243-248, Tokyo, Japan, September 1995.

[10] X. Fu, Q. Sheng, Y. Zhang, J. Chen, S. Zhang, and Z. Zhang, "Computation of the safety factor for slope stability using discontinuous deformation analysis and the vector sum method," Computers and Geotechnics, vol. 92, pp. 68-76, 2017.

[11] H. R. Cedergren, Seepage, Drainage, and Flow Nets, Wiley, New York, NY, USA, 3rd edition, 1997.

[12] Q. J. Pan, J. S. Xu, and D. Daniel, "Three-dimensional stability of a slope subjected to seepage forces," International Journal of Geomechnics, vol. 17, no. 8, Article ID 04017035, 2017.

[13] H. Zheng, L. G. Tham, and D. Liu, "On two definitions of the factor of safety commonly used in the finite element slope stability analysis," Computers and Geotechnics, vol. 33, no. 3, pp. 188-195, 2006.

[14] Geo-Slope International Ltd., Seepage Modeling with SEEP/W, Geo-Slope International Ltd., Calgary, Canada, 2007.

[15] X. R. Ge, "The vector sum method: a new approach to calculating the safety factor of stability against sliding for slope engineering and dam foundation problems," in Proceedings of the International Symposium on Geo-Environmental Engineering, pp. 99-110, Hangzhou, China, September 2010.

[16] Z. Wu, "New analysis method for slope stability considering force-vector characteristics," Journal of Geotechnical and Geoenvironmental Engineering, vol. 139, no. 10, pp. 18131816, 2013.

[17] G. Liu, X. Zhuang, and Z. Cui, “Three-dimensional slope stability analysis using independent cover based numerical manifold and vector method," Engineering Geology, vol. 225, pp. 83-95, 2017.

[18] A. W. Bishop, "The use of the slip circle in the stability analysis of slopes,” Géotechnique, vol. 5, no. 1, pp. 7-17, 1955.

[19] A. W. Bishop and N. Morgenstern, "Stability coefficients for earth slopes," Géotechnique, vol. 10, no. 4, pp. 129-153, 1960.

[20] N. R. Morgenstern and V. E. Price, "The analysis of the stability of general slip surfaces," Géotechnique, vol. 15, no. 1, pp. 79-93, 1965.

[21] E. Spencer, "A method of analysis of the stability of embankments assuming parallel inter-slice forces," Géotechnique, vol. 17, no. 1, pp. 11-26, 1967.

[22] Geo-Slope International Ltd., Stability Modeling with SLOPE/ W, Geo-Slope International Ltd., Calgary, Canada, 2007.

[23] H. Zheng, G. Sun, and D. Liu, "A practical procedure for searching critical slip surfaces of slopes based on the strength reduction technique," Computers and Geotechnics, vol. 36, no. 1-2, pp. 1-5, 2009.

[24] M. W. Guo, "Study on the vector sum analysis method of slope and dam foundation stability against sliding and its engineering application," Dissertation, Chinese Academy of Sciences, Institute of Rock and Soil Mechanics, Wuhan, China, 2010. 


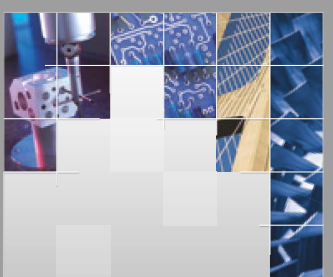

\section{Enfincering}
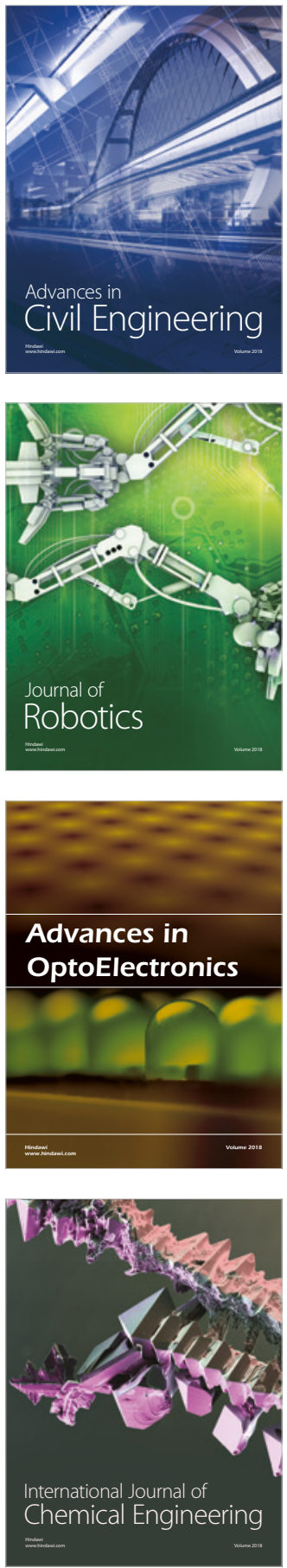

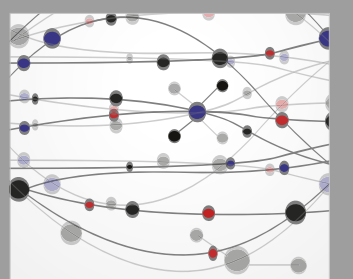

\section{Rotating \\ Machinery}

The Scientific World Journal

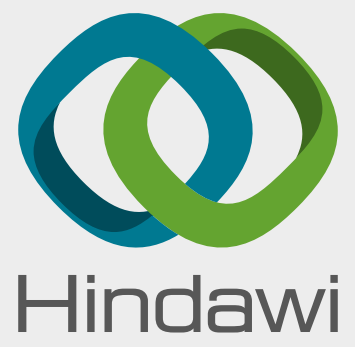

Submit your manuscripts at

www.hindawi.com
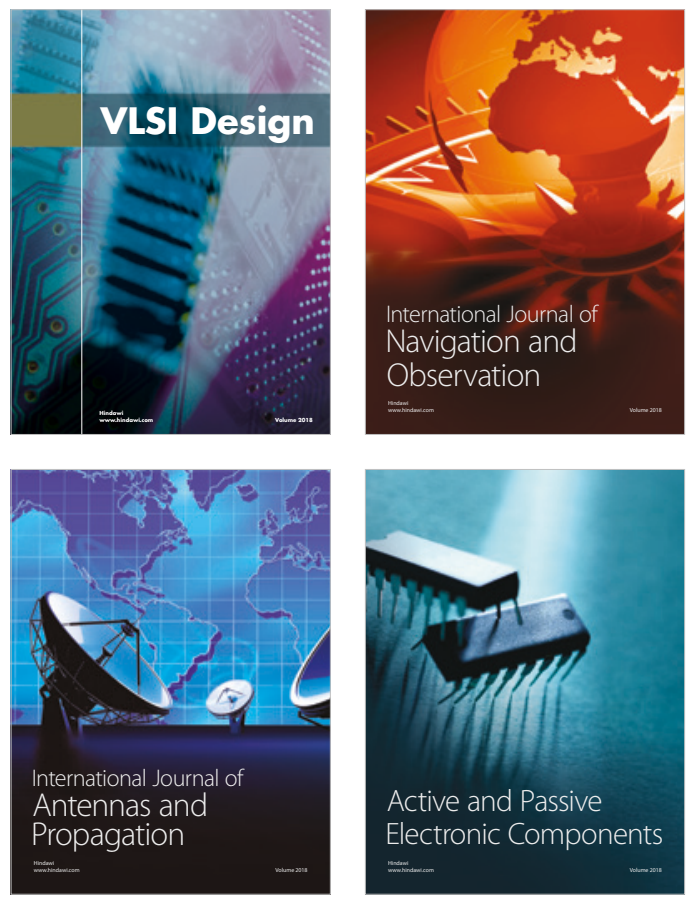
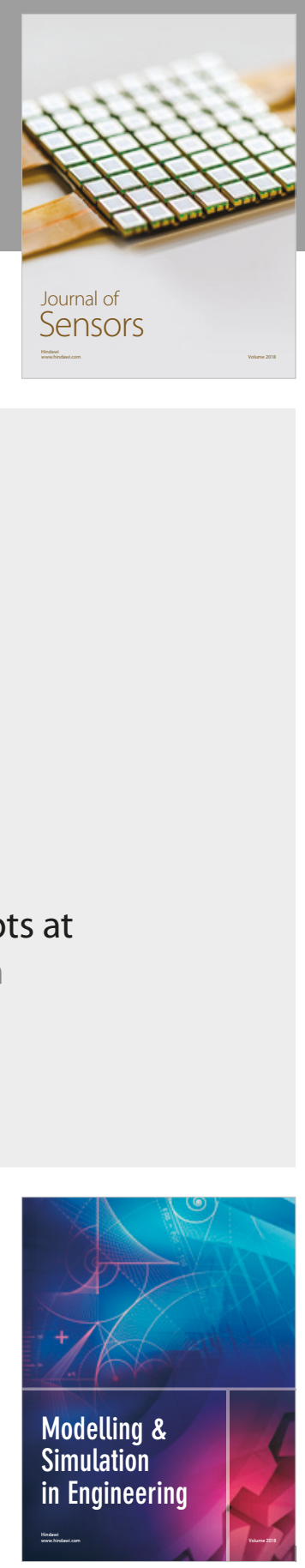

\section{Advances \\ Multimedia}
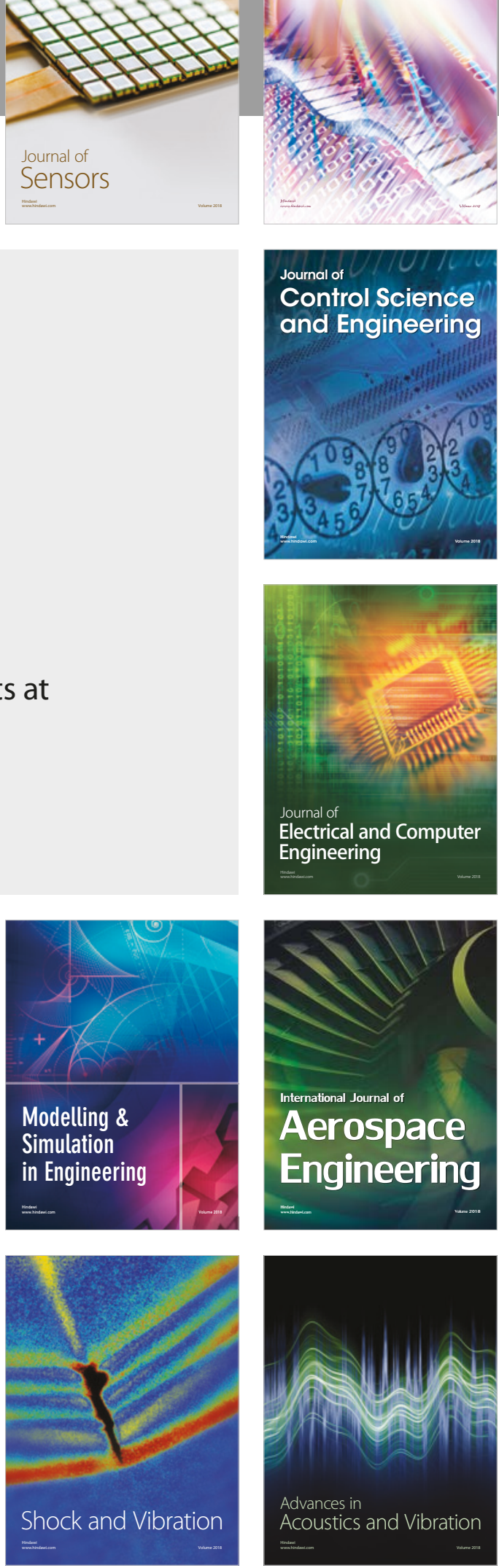